\title{
Correction to: Novel promising serum biomarkers for canine mammary tumors
}

\author{
Afnan Saleem ${ }^{1} \cdot$ G. K. Megha ${ }^{2} \cdot$ Asima Zehra $^{3}$
}

Published online: 2 July 2021

(C) Indian National Science Academy 2021

\section{Correction to: \\ Proceedings of the Indian National Science Academy https://doi.org/10.1007/s43538-021-00035-4}

In this article the affiliation details for the authors were incorrectly given. This has been corrected now.

No other changes to the article have been made. We apologise for any inconvenience caused to our readers.

The original article can be found online at https://doi.org/10.1007/ s43538-021-00035-4.

Afnan Saleem

afnankhan1082@gmail.com

G. K. Megha

meghagopalakrishna29@gmail.com

Asima Zehra

assimazehra@gmail.com

1 Division of Animal Biotechnology, Faculty of Veterinary

Sciences \& Animal Husbandry, SKUAST-Kashmir, Badgam,

Shalimar, Jammu and Kashmir, India

2 Division of Veterinary Public Health and Epidemiology, IVRI Izzatnagar, Bareilly, India

3 School of Public Health \& Zoonoses, GADVASU, Ludhiana, India 